\title{
Uma Análise da Desigualdade do Crédito entre os Municípios do Estado do Rio de Janeiro: 2000-2014
}

\section{An Assessment of Credit Inequality between the Cities of the State of Rio de Janeiro: 2000-2014}

\author{
Luciana da Cruz Thomazi ${ }^{\mathrm{a}}$ \\ Luiz Fernando de Paula
}

\begin{abstract}
Resumo: O objetivo deste artigo é analisar a distribuição regional do crédito no estado do Rio de Janeiro, em particular o comportamento de agências e a distribuição do movimento financeiro bancário, e suas relações com a dinâmica de desenvolvimento econômico no estado. Para tanto, são construídos indicadores a partir de dados relativos à atividade econômica e do balanço consolidado das agências bancárias dos 92 municípios fluminenses para o período de 2000 a 2014. Através da análise desses indicadores, conclui-se que, a despeito da forte concentração econômica e de crédito na região metropolitana do estado, as cidades do interior vêm apresentando um dinamismo diferenciado, evidenciando certa tendência à desconcentração do crédito, acompanhando a tendência de desconcentração econômica. Logo, reforça a relação entre desenvolvimento econômico e financeiro e a concepção de que o movimento financeiro se concentra no entorno de cidades de forte dinamismo econômico.
\end{abstract}

Palavras-chave: Economia regional. Setor bancário. Desigualdade na oferta de crédito.

\begin{abstract}
The objective of this paper is to analyze the regional distribution of credit in the state of Rio de Janeiro, Brazil, in particular the behavior of agencies and the distribution of financial turnover banking and its relations with the dynamics of economic development in the state of Rio de Janeiro. To reach this objective, indicators were built from data on economic activity and the consolidated balance sheet of banks of 92 municipalities of Rio de Janeiro for the period 2000 to 2014. Through the analysis of these indicators is concluded that despite the strong economic concentration and credit in the metropolitan area of the state of Rio de Janeiro, the inner cities have shown a dynamic differentiated from the metropolitan area showing a certain tendency towards decentralization of credit, following the trend of economic decentralization, strengthening the link between economic and financial development and the design that focuses on financial flow around cities with strong economic dynamism.
\end{abstract}

Keywords: Regional economy. Banking sector. Inequality in the credit supply.

\footnotetext{
Universidade do Estado do Rio de Janeiro (UERJ), Programa de Pós-graduação em Ciências Econômicas (PPGCE). Rio de Janeiro, Rio de Janeiro, Brasil.

b Universidade Federal do Rio de Janeiro (UFRJ), Instituto de Economia (IE). Rio de Janeiro, Rio de Janeiro, Brasil.

Universidade do Estado do Rio de Janeiro (UERJ), Instituto de Estudos Políticos e Sociais (IESP). Rio de Janeiro, Rio de Janeiro, Brasil.

d Conselho Nacional de Desenvolvimento Científico e Tecnológico (CNPq). Brasília, Brasil.

Fundação Carlos Chagas Filho de Amparo à Pesquisa do Estado do Rio de Janeiro (FAPERJ). Rio de Janeiro, Rio de Janeiro, Brasil.
} 
JEL Classification: R11; G21.

\section{Introdução}

A partir da estabilização monetária, o sistema bancário do Brasil passou por uma aceleração do processo de consolidação, impulsionado pelo fim do ganho inflacionário e por programas governamentais como o Programa de Estímulo à Reestruturação e ao Fortalecimento do Sistema Financeiro Nacional (Proer) e o Programa de Incentivo à Redução do Setor Público Estadual na Atividade Bancária (Proes). O objetivo principal desses programas era tornar o sistema bancário menos vulnerável a choques. Dessa forma, a partir de 1994 observam-se no Brasil dois movimentos: a concentração geográfica das agências e a redução do número de sedes bancárias, resultado do processo de fusões e aquisições, além das liquidações, também com concentração regional.

No que tange à concessão do crédito, os bancos atuam de forma a obter a maior gama de informações possíveis do tomador, visando reduzir sua exposição ao risco. Os bancos também possuem preferência pela liquidez e buscam se proteger de situações em que a informação disponível é baixa ou de qualidade ruim. Todavia, em um território de regiões centrais e periféricas, onde a periferia, além de ter um menor grau de desenvolvimento, se caracteriza por ser mais instável, é natural se supor que os bancos disponibilizem maior volume de recursos para a região central. Com a consolidação do setor bancário, e consequente redução de agências e fechamento de sedes nas periferias, a informação sobre essas regiões passa a ser ainda mais difícil para os bancos sediados no centro. Esse mecanismo tende a reduzir o crédito concedido justamente para as regiões menos desenvolvidas, retroalimentando um processo de desigualdade.

De acordo com Freitas e Paula (2010), o número de instituições financeiras de cunho mais regional no Brasil sofreu forte redução, em especial os bancos estaduais e os privados de porte médio com foco principal em seus estados e regiões de atuação, e submeteu, também, as regiões menos desenvolvidas às decisões estratégicas de grandes grupos bancários nacionais e estrangeiros sediados, em sua maioria, na cidade de São Paulo. Segundo Vasconcelos et al. (2004), o número de municípios sem agências aumentou no período de 1994 a 2002, o que parece evidenciar uma exclusão financeira de parte da população brasileira e um precário acesso ao atendimento bancário.

No entanto, esse não é um processo sem maiores implicações para o resto da economia. Existe um conjunto de trabalhos no âmbito internacional que busca identificar a relação existente entre desenvolvimento financeiro e crescimento econômico. Há indícios apontando para um efeito positivo e relevante do desenvolvimento financeiro sobre o crescimento econômico, e, além disso, já se pode 
tomar como consensual a importância do sistema bancário e do crédito para o bom funcionamento da economia (LEVINE, 1997; PAULA, 2014).

No Brasil, a literatura econômica nacional acompanhou esse debate fazendo análises sobre a realidade brasileira. Conforme os estudos de Matos (2002) e Araújo e Dias (2006), o desenvolvimento do sistema financeiro afeta positivamente a taxa de crescimento da economia brasileira; usando técnicas econométricas diversas Matos (2002) e Araújo e Dias (2006) mostram que é positiva a causalidade entre desenvolvimento financeiro e crescimento econômico para o país. Reichstul e Lima (2006), por sua vez, identificam uma causalidade bidirecional entre as duas variáveis.

Por outro lado, há uma extensa literatura empírica que mostra que a consolidação do setor bancário brasileiro tem acentuado a concentração regional do crédito (e econômica) no país (AMADO, 1998; ALMEIDA, 2007; FREITAS; PAULA, 2010) e, ainda, que a maior preferência pela liquidez dos bancos na periferia (regiões ou estados menos desenvolvidos) igualmente tem gerado maior concentração regional do crédito (MENEZES et al., 2007; FREITAS; PAULA, 2010; SORGATO; FERREIRA JR., 2014). No último caso, argumenta-se que haveria um processo de causação cumulativa, no qual a diminuição da preferência pela liquidez do centro reduz a oferta de crédito na periferia, visto que a oferta se desloca para regiões onde haja maior demanda ${ }^{1}$ (DOW, 1993; CAVALCANTE; CROCCO; GONZAGA, 2004).

Sem ter o objetivo de esgotar esta questão aqui, a assertiva estatística é suficiente para a abordagem da questão, ou seja, a evidência de relação positiva entre desenvolvimento financeiro e crescimento econômico, independente da direção da causalidade, e entre consolidação bancária e preferência pela liquidez dos bancos e concentração regional do crédito é suficiente para os propósitos deste artigo.

Se por um lado há uma extensa literatura empírica sobre a preferência pela liquidez dos bancos, concentração regional do crédito e desenvolvimento econômico no Brasil, por outro lado há poucos estudos sobre essas questões a nível estadual. Seguindo essa abordagem da preferência pela liquidez dos bancos e suas relações com o crédito e o desenvolvimento econômico, Nogueira, Crocco e Figueiredo(2009) investigam a existência, no estado de Minas Gerais, de estratégias bancárias diferenciadas no território, concluindo, através da análise do balanço consolidado das agências bancárias, que os bancos agem de forma desigual no espaço, aprofundando as desigualdades no estado.

Nessa linha, o presente artigo tem por objetivo analisar a distribuição regional do crédito no estado do Rio de Janeiro, em particular o comportamento de agências e a distribuição do movimento financeiro bancário, e suas relações

1 Dow (1993) argumenta que um aumento na preferência pela liquidez em uma localidade, causando o aumento da demanda pela moeda, induz à queda do preço de todos os outros ativos em relação à moeda, além de encorajar a saída de capital para regiões centrais, para centros financeiros. Isso reduz a oferta de depósitos em regiões periféricas e, consequentemente, diminui a oferta de crédito por parte das instituições financeiras das regiões periféricas. 
com a dinâmica de desenvolvimento econômico através da análise do balanço consolidado das agências bancárias (utilizando dados do Banco Central do Brasil - BCB), metodologia semelhante à utilizada por Nogueira, Crocco e Figueiredo (2009) para o estado de Minas Gerais. Se desconhece trabalhos realizados analisando a distribuição do crédito nas regiões do estado do Rio de Janeiro. Para tanto, na seção 2, efetua-se uma breve análise da economia fluminense nos anos 2000 com foco na economia regional. Já, na seção 3, analisam-se vários aspectos das estratégias bancárias diferenciadas no espaço do estado do Rio de Janeiro. Para tanto, são elaborados indicadores com base nos dados do balanço consolidado das agências bancárias e em dados relativos à atividade econômica de todos os municípios fluminenses para o período de 2000 a $2014 .{ }^{2}$ Por fim, a seção 4 sumaria os principais resultados do trabalho e tece as considerações finais.

Os dados utilizados neste trabalho foram extraídos de duas fontes básicas: IBGE e BCB. O IBGE mudou a metodologia de cálculo do PIB e fez a retropolação da série, revisando toda a série do PIB, por isso verifica-se a mudança na série no período de 2000 a 2009. Já o BCB disponibilizava as informações bancárias através de um sistema chamado Sisbacen. O acesso a esse sistema foi descontinuado em 25 de abril de 2016. As informações de balanço foram disponibilizadas no site do BCB através da transferência de arquivos denominados "Saldos Estban", gerados mensalmente, contemplando a posição mensal dos saldos das principais rubricas de balancetes dos bancos comerciais e dos bancos múltiplos com carteira comercial, por município. ${ }^{3}$

De modo geral, os resultados obtidos na pesquisa realizada revelam que, a despeito da concentração econômica e de crédito na região metropolitana do estado do Rio de Janeiro, as cidades do interior vêm apresentando um dinamismo diferenciado evidenciando certa tendência à desconcentração do crédito, acompanhando o movimento de crescimento da atividade econômica nesses municípios, reforçando a relação entre desenvolvimento econômico e financeiro.

\section{Economia Fluminense: uma Breve Avaliação do Período Recente}

O estado do Rio de Janeiro está localizado na região Sudeste do Brasil, fazendo fronteira com os estados do Espírito Santo, São Paulo e Minas Gerais e formando uma área de 43.696,054 Km². É composto por 92 municípios, incluindo a capital, a cidade do Rio de Janeiro. A Secretaria de Planejamento e Gestão do

2 O período escolhido se deve à disponibilidade de dados por município, como o PIB. O ano de 2014 é o último ano de PIB municipal disponibilizado pelo IBGE até o momento de realização deste artigo.

3

Comparando-se a série retirada do Sisbacen com as obtidas pelo arquivo "Saldos Estban", observou-se que eram diferentes. Dessa forma, toda a série foi revisada tendo como fonte o arquivo

"Saldos Estban" para manter a coerência das informações. 
Estado do Rio de Janeiro o subdivide em oito regiões: metropolitana, ${ }^{4}$ centro-sul, ${ }^{5}$ Costa Verde, ${ }^{6}$ baixadas litorâneas, ${ }^{7}$ médio Paraíba, ${ }^{8}$ noroeste,,${ }^{9}$ norte ${ }^{10}$ e serrana. ${ }^{11}$

A Tabela 1 apresenta os principais indicadores que mostram o desempenho fluminense no período de 2000 a 2014. Entre as atividades de maior importância na economia fluminense, pode-se destacar a indústria associada à exploração de petróleo, a indústria naval e as indústrias siderúrgica e automobilística.

Tabela 1 - PIB e população do estado do Rio de Janeiro

\begin{tabular}{lccc}
\hline & PIB (em mil reais)* & PIB per capita* & População \\
\hline 2000 & 342.068 .952 & 24.550 & 13.933 .756 \\
2001 & 345.057 .761 & 23.701 & 14.558 .545 \\
2002 & 358.251 .536 & 24.330 & 14.724 .475 \\
2003 & 354.275 .927 & 23.810 & 14.879 .118 \\
2004 & 365.679 .860 & 24.052 & 15.203 .750 \\
2005 & 376.468 .013 & 24.472 & 15.383 .407 \\
2006 & 391.420 .074 & 25.153 & 15.561 .720 \\
2007 & 405.542 .830 & 26.299 & 15.420 .375 \\
2008 & 422.362 .352 & 26.610 & 15.872 .362 \\
2009 & 430.637 .667 & 26.897 & 16.010 .429 \\
2010 & 449.860 .111 & 28.128 & 15.993 .583 \\
2011 & 461.740 .300 & 28.657 & 16.112 .678 \\
2012 & 471.147 .526 & 29.027 & 16.231 .365 \\
2013 & 477.230 .037 & 29.154 & 16.369 .179 \\
2014 & 484.528 .509 & 29.435 & 16.461 .173 \\
\hline & & & continua...
\end{tabular}

4 Metropolitana: Belford Roxo, Duque de Caxias, Guapimirim, Itaboraí, Itaguaí, Japeri, Magé, Mesquita, Nilópolis, Niterói, Nova Iguaçu, Paracambi, Queimados, Rio de Janeiro, São Gonçalo, São João de Meriti, Seropédica e Tanguá.

5 Centro-sul: Areal, Comendador Levy Gasparian, Engenheiro Paulo de Frontin, Mendes, Miguel Pereira, Paraíba do Sul, Paty dos Alferes, Sapucaia, Três Rios e Vassouras.

6 Costa Verde: Angra dos Reis, Mangaratiba e Parati.

7 Baixadas litorâneas: Araruama, Armação dos Búzios, Arraial do Cabo, Cabo Frio, Cachoeiras de Macacu, Casimiro de Abreu, Iguaba Grande, Maricá, Rio Bonito, Rio das Ostras, São Pedro da Aldeia, Saquarema e Silva Jardim.

8 Médio Paraíba: Barra do Piraí, Barra Mansa, Itatiaia, Pinheiral, Piraí, Porto Real, Quatis, Resende, Rio Claro, Rio das Flores, Valença e Volta Redonda.

9 Noroeste: Aperibé, Bom Jesus do Itabapoana, Cambuci, Italva, Itaocara, Itaperuna, Laje de Muriaé, Miracema, Natividade, Porciúncula, Santo Antônio de Pádua, São José de Ubá e Varre-Sai.

10 Norte: Campos dos Goytacazes, Carapebus, Cardoso Moreira, Conceição de Macabu, Macaé, Quissamã, São Fidelis, São Francisco de Itabapoana e São João da Barra.

11 Serrana: Bom Jardim, Cantagalo, Carmo, Cordeiro, Duas Barras, Macuco, Nova Friburgo, Petrópolis, Santa Maria Madalena, São José do Vale do Rio Preto, São Sebastião do Alto, Sumidouro, Teresópolis e Trajano de Moraes. 


\begin{tabular}{cccc} 
& PIB (em mil reais)* & PIB per capita* & População \\
\hline Variação & 41,65 & 19,90 & 18,14 \\
\hline
\end{tabular}

Fonte: IBGE (2017).

Nota: *PIB a preços de 2010.

Durante o século XX, a economia do estado do Rio de Janeiro foi a segunda maior do Brasil, sendo ultrapassada apenas pela paulista, entretanto, no período compreendido entre o início dos anos 1980 e a primeira metade dos anos 1990, o estado do Rio de Janeiro vivenciou uma profunda crise econômica, social e institucional (BARRAL NETO; SILVA NETO, 2008). A partir de meados da década de 1990, entretanto, a economia fluminense voltou a apresentar sinais de dinamismo (SANTOS, 2003; NATAL, 2005).

Para Santos (2009), a retomada do crescimento estadual vem ocorrendo com melhor redistribuição espacial do PIB, ou seja, a polarização da produção na região metropolitana (cerca de $80 \%$ ) está diminuindo. Além disso, as cidades médias, com população superior a 100 mil habitantes, com exceção da capital, estão ganhando espaço, principalmente aquelas localizadas no interior fluminense, isto é, fora dos limites da região metropolitana.

Segundo estimativas do IBGE, em 2014, 16.461.173 pessoas habitavam o estado do Rio de Janeiro, desse total cerca de 70\% residiam na região metropolitana, caracterizando-a como a metrópole mais concentrada do país (SANTOS, 2003). Entretanto, nos últimos anos, a tendência vem se revertendo devido às novas dinâmicas econômicas engendradas no interior (municípios fora da região metropolitana), em grande parte associadas à exploração de petróleo e gás na Bacia de Campos. ${ }^{12}$

Para o Ibam (2009), está ocorrendo um processo de interiorização, isto é, o desenvolvimento das atividades econômicas no estado do Rio de Janeiro vem ocorrendo de forma descentralizada no território fluminense, por meio de investimentos nos setores metal-mecânico e automobilístico na região do médio Paraíba, na indústria naval em Niterói (região metropolitana) e Angra dos Reis (região da Costa Verde), em confecções na região serrana e, principalmente, na indústria extrativista de petróleo e gás.

A Tabela 2 apresenta a participação das regiões no PIB do estado.

12 Os municípios que compõem a Bacia de Campos são: Armação de Búzios, Cabo Frio, Campos dos Goytacazes, Carapebus, Casemiro de Abreu, Macaé, Quissamã, Rio das Ostras e São João da Barra (PIQUET, 2003). Esse grupo de municípios não coincide com nenhuma região segundo a Tabela 2 . 
Tabela 2 - Participação das regiões no PIB fluminense (\%)

\begin{tabular}{lcccccccc}
\hline & Noroeste & Norte & $\begin{array}{c}\text { Serra- } \\
\text { na }\end{array}$ & $\begin{array}{c}\text { Baixadas } \\
\text { litorâneas }\end{array}$ & $\begin{array}{c}\text { Médio } \\
\text { Paraíba }\end{array}$ & $\begin{array}{c}\text { Centro- } \\
\text { sul }\end{array}$ & $\begin{array}{c}\text { Costa } \\
\text { Verde }\end{array}$ & $\begin{array}{c}\text { Metro- } \\
\text { politana }\end{array}$ \\
\hline 2000 & 1,07 & 9,52 & 3,60 & 4,77 & 6,21 & 1,10 & 1,79 & 71,93 \\
2001 & 1,01 & 9,58 & 3,42 & 5,00 & 6,22 & 1,07 & 1,86 & 71,84 \\
2002 & 0,96 & 10,92 & 3,57 & 5,86 & 5,93 & 1,01 & 1,82 & 69,93 \\
2003 & 0,98 & 11,97 & 3,45 & 6,16 & 6,35 & 1,04 & 1,54 & 68,52 \\
2004 & 0,90 & 11,79 & 3,25 & 6,12 & 6,96 & 0,95 & 2,15 & 67,88 \\
2005 & 0,97 & 14,57 & 3,03 & 8,47 & 5,68 & 0,87 & 2,00 & 64,42 \\
2006 & 0,93 & 16,43 & 3,14 & 9,30 & 5,37 & 0,93 & 1,86 & 62,04 \\
2007 & 0,85 & 14,77 & 3,17 & 7,96 & 5,68 & 0,94 & 2,15 & 64,48 \\
2008 & 0,93 & 18,66 & 3,27 & 8,31 & 6,39 & 0,90 & 2,06 & 59,48 \\
2009 & 0,93 & 13,28 & 3,72 & 6,44 & 5,94 & 1,06 & 2,09 & 66,53 \\
2010 & 0,87 & 14,22 & 3,56 & 6,84 & 6,69 & 1,07 & 1,98 & 64,77 \\
2011 & 0,87 & 15,88 & 3,61 & 8,02 & 5,95 & 1,01 & 2,00 & 62,66 \\
2012 & 0,88 & 16,03 & 3,55 & 9,58 & 5,73 & 1,06 & 2,08 & 61,10 \\
2013 & 0,89 & 14,78 & 3,29 & 8,89 & 5,94 & 1,09 & 1,95 & 63,17 \\
2014 & 0,99 & 14,25 & 3,57 & 8,78 & 5,41 & 1,18 & 2,21 & 63,61 \\
Média & 0,94 & 13,78 & 3,42 & 7,37 & 6,03 & 1,02 & 1,97 & 65,49 \\
\hline
\end{tabular}

Fonte: IBGE (2017).

Como pode-se ver, a região metropolitana é responsável, em média, por 65,49\% do PIB fluminense, embora sua participação venha decrescendo.

A segunda região com maior participação média no PIB estadual é a região norte (13,78\%), que alcançou seu maior índice em 2008, 18,66\%. Os municípios de Macaé e Campos são os que mais se destacam nessa região.

A região das baixadas litorâneas obteve, em média, a terceira maior participação no PIB estadual. No período de 2000 a 2004, foi ultrapassada pela região do médio Paraíba, mas, de 2005 em diante, alcançou a terceira maior participação no PIB estadual, registrando sua maior participação em 2012 (9,58\%). Vale lembrar que a atividade de petróleo e gás é predominante nessa região. Se somadas as participações médias das regiões norte e baixadas litorâneas, ver-se-á que respondem por $21,15 \%$ da produção estadual, alcançando $26,97 \%$ em 2008.

A região do médio Paraíba obteve, em média, a quarta maior participação no PIB estadual no período 2000/2014. A atividade produtiva de maior destaque nessa região é a automobilística, e o principal município é Volta Redonda.

Em 2000, 2005, 2009 e 2014, os municípios que mais se destacaram na evolução do PIB estadual foram: Rio de Janeiro, Campos dos Goytacazes, Duque de 
Caxias, Niterói, São Gonçalo, Nova Iguaçu, Volta Redonda, Petrópolis, Cabo Frio e Macaé (ver Tabela 3).

Tabela 3 - Ranking dos dez municípios com maior participação no PIB fluminense (\%)

\begin{tabular}{|c|c|c|c|}
\hline \multicolumn{2}{|c|}{2000} & \multicolumn{2}{|c|}{2005} \\
\hline Rio de Janeiro & 53,26 & Rio de Janeiro & 45,71 \\
\hline Campos & 6,02 & Campos & 9,98 \\
\hline Duque de Caxias & 4,16 & Duque de Caxias & 6,54 \\
\hline Niterói & 3,11 & Rio das Ostras & 2,91 \\
\hline Nova Iguaçu & 2,57 & Macaé & 2,78 \\
\hline São Gonçalo & 2,53 & Cabo Frio & 2,71 \\
\hline Volta Redonda & 2,47 & Niterói & 2,70 \\
\hline Macaé & 1,94 & São Gonçalo & 2,19 \\
\hline Rio das Ostras & 1,67 & Volta Redonda & 2,03 \\
\hline Petrópolis & 1,48 & Nova Iguaçu & 2,01 \\
\hline \multicolumn{2}{|c|}{2009} & \multicolumn{2}{|c|}{2014} \\
\hline Rio de Janeiro & 47,85 & Rio de Janeiro & 44,68 \\
\hline Campos & 8,06 & Campos & 8,64 \\
\hline Duque de Caxias & 5,36 & Duque de Caxias & 4,27 \\
\hline Macaé & 3,05 & Niterói & 3,65 \\
\hline Niterói & 2,80 & Macaé & 3,14 \\
\hline Nova Iguaçu & 2,35 & Cabo Frio & 2,57 \\
\hline São Gonçalo & 2,29 & São Gonçalo & 2,31 \\
\hline Volta Redonda & 1,97 & Nova Iguaçu & 2,26 \\
\hline Rio das Ostras & 1,96 & Rio das Ostras & 2,13 \\
\hline Cabo Frio & 1,90 & Petrópolis & 1,69 \\
\hline
\end{tabular}

Fonte: IBGE (2017).

O desempenho de Duque de Caxias pode ser explicado pela presença da Refinaria Duque de Caxias ${ }^{13}$ (Reduc) em seu território, que atrai diversas empresas dos ramos químico e petroquímico. Outro fator determinante para o nível de atividade econômica em Caxias é a influência exercida pela economia carioca devido à proximidade com o município do Rio de Janeiro. Dessa Forma, Caxias, juntamente com outros subcentros, como Nova Iguaçu, Niterói, São Gonçalo e São João de Meriti, representam a parte mais dinâmica da periferia metropolitana do

13 Segundo Bueno e Casarin (2011), há duas refinarias no estado do Rio de Janeiro: Reduc e Manguinhos. As duas, em conjunto, são responsáveis pelo refino de 12\% do petróleo nacional. 
Rio, que, na medida em que abrigam grandes contingentes populacionais, concentram muitas atividades de comércio e serviços (IBAM, 2009).

As trajetórias de Campos e Macaé estão associadas aos recursos financeiros oriundos do petróleo: o primeiro é o município que mais recebe royalties e participações especiais, além de ser um polo urbano tradicional na região desde o ciclo da cana de açúcar (PIQUET, 2003); e Macaé, denominada localmente como "capital do petróleo", é a segunda economia da região norte do estado e sede das atividades de exploração de petróleo e gás na plataforma continental (CRESPO, 2003).

A posição de Volta Redonda pode ser explicada pela presença da Companhia Siderúrgica Nacional, responsável por grande parte da produção siderúrgica do estado e considerada um marco no desenvolvimento da região do médio Vale do Paraíba. Outro fator que contribui para o seu desempenho é a localização geográfica, visto que está situada entre as cidades de São Paulo (maior metrópole nacional), Rio de Janeiro (segunda metrópole nacional) e o estado de Minas Gerais (SILVA, 2007).

Embora as cidades do interior estejam crescendo, a importância da região metropolitana e do município do Rio de janeiro é grande, o que pode ser confirmado pelos dados de participação no PIB estadual. A economia carioca exerce grande influência sobre o nível de atividade da região metropolitana, em especial sobre Duque de Caxias, Nova Iguaçu, Niterói, São Gonçalo e São João de Meriti. Esses municípios representam a parte mais dinâmica da periferia metropolitana, conforme visto anteriormente.

Na próxima seção, analisa-se como o crédito se distribui no território fluminense e se segue a mesma tendência de desconcentração espacial da produção. 


\section{Estratégias Bancárias Diferenciadas no Espaço: o Caso do Rio de Janeiro}

Optou-se, nesta seção, por se dividir os 92 municípios fluminenses com dados financeiros para o período de 2000 a 2014 tomando-se como referência o PIB de 2005. ${ }^{14}$ Dessa forma, as cidades foram agregadas em cinco categorias: $:^{15}$

a) grupo 1: localidades com PIB entre $R \$ 50$ milhões e $R \$ 200$ milhões;

b) grupo 2: localidades com PIB entre $R \$ 200$ milhões e $R \$ 600$ milhões;

c) grupo 3: localidades com PIB superior a $\mathrm{R} \$ 600$ milhões;

d) grupo 4: região metropolitana do Rio de Janeiro; e

e) grupo 5: município do Rio de Janeiro.

A alocação dos municípios em grupos tem como objetivo facilitar a sua análise. Ao se agregar localidades com peso econômico semelhante, tem-se como hipótese subjacente o fato de o sistema bancário guiar suas estratégias - tanto de localização, quanto de alocação de recursos -, em parte, com base nessa variável. A opção de isolar o município do Rio de Janeiro se justifica por seu peso econômico no PIB fluminense, conforme pode ser visto na Tabela 4. Cabe destacar que tal agrupamento, justificável para avaliar a relação entre distribuição de crédito e desenvolvimento econômico, tem restrições, pois a amostra em cada grupo pode ser heterogênea em função da existência de municípios de tamanho grande e de tamanho pequeno.

14 Critério de agrupamento dos municípios segundo faixas do PIB de 2005, conforme o utilizado por Nogueira, Crocco e Figueiredo (2009) para os municípios de Minas Gerais.

15 Composição dos grupos baseada nos critérios de Nogueira, Crocco e Figueiredo (2009). Grupo 1: Aperibé, Areal, Bom Jardim, Cambuci, Cardoso Moreira, Carmo, Comendador Levy Gasparian, Conceição de Macabu, Cordeiro, Duas Barras, Engenheiro Paulo Frontin, Iguaba Grande, Italva, Itaocara, Laje do Muriaé, Macuco, Mendes, Miracema, Natividade, Paty do Alferes, Pinheiral, Porciúncula, Quatis, Rio Claro, Santa Maria Madalena, São José de Ubá, São José do Vale do Rio Preto, São Sebastião do alto, Sapucaia, Silva Jardim, Sumidouro, Trajano de Moraes e Varre-Sai. Grupo 2: Arraial do Cabo, Bom Jesus do Itabapoana, Cachoeiras de Macacu, Cantagalo, Carapebus, Mangaratiba, Miguel Pereira, Paraíba do Sul, Parati, Rio das Flores, Santo Antônio de Pádua, São Fidelis, São Francisco do Itabapoana, São Pedro da Aldeia, Saquarema, Valença e Vassouras. Grupo 3: Angra dos Reis, Araruama, Armação dos Búzios, Barra do Piraí, Barra Mansa, Cabo Frio, Campo dos Goytacazes, Casimiro de Abreu, Itaperuna, Itatiaia, Macaé, Maricá, Nova Friburgo, Petrópolis, Piraí, Porto Real, Quissamã, Resende, Rio Bonito, Rio das Ostras, São João da Barra, Teresópolis, Três Rios e Volta Redonda. Grupo 4: Belford Roxo, Duque de Caxias, Guapimirim, Itaboraí, Itaguaí, Japeri, Magé, Mesquita, Nilópolis, Niterói, Nova Iguaçu, Paracambi, Queimados, Rio de Janeiro, São Gonçalo, São João de Meriti, Seropédica e Tanguá. 
Tabela 4 - Participação dos grupos no PIB do estado do Rio de Janeiro

\begin{tabular}{lccccc}
\hline & Grupo 1 & Grupo 2 & Grupo 3 & Região metropolitana* & $\begin{array}{c}\text { Município do } \\
\text { Rio de Janeiro }\end{array}$ \\
\hline 2000 & 1,65 & 2,71 & 23,71 & 71,93 & 53,26 \\
2001 & 1,63 & 2,73 & 23,80 & 71,84 & 52,73 \\
2002 & 1,56 & 2,69 & 25,82 & 69,93 & 51,17 \\
2003 & 1,55 & 2,56 & 27,36 & 68,52 & 49,01 \\
2004 & 1,64 & 2,87 & 27,60 & 67,88 & 49,15 \\
2005 & 1,39 & 2,70 & 31,50 & 64,42 & 45,71 \\
2006 & 1,36 & 2,57 & 34,02 & 62,04 & 44,23 \\
2007 & 1,40 & 2,63 & 31,49 & 64,48 & 44,68 \\
2008 & 1,52 & 2,65 & 36,35 & 59,48 & 43,07 \\
2009 & 1,56 & 2,81 & 29,10 & 66,53 & 47,85 \\
2010 & 1,49 & 2,72 & 31,02 & 64,77 & 46,27 \\
2011 & 1,42 & 2,75 & 33,17 & 62,66 & 44,77 \\
2012 & 1,36 & 3,21 & 34,33 & 61,10 & 44,04 \\
2013 & 1,40 & 3,17 & 32,26 & 63,17 & 45,25 \\
2014 & 1,51 & 3,20 & 31,68 & 63,61 & 44,68 \\
Média & 1,50 & 2,80 & 30,21 & 65,49 & 47,06 \\
\hline
\end{tabular}

Fonte: IBGE (2017).

Nota: ${ }^{*}$ ) Inclui o município do Rio de Janeiro.

A participação da produção carioca corresponde a mais de $40 \%$ do PIB estadual em todo o período, respondendo por mais da metade do PIB fluminense de 2000 a 2002. A região metropolitana é muito influenciada pela participação do município do Rio de Janeiro e é responsável por mais de 60\% do PIB estadual, ficando abaixo desse percentual apenas no ano de 2008. Já o grupo 3 é composto por Campos e Macaé, municípios cujas economias estão fortemente associadas às atividades petrolíferas, conforme visto na seção anterior.

\subsection{O Tamanho Regional do Sistema Bancário Fluminense}

De acordo com a literatura acerca da relação entre desenvolvimento do sistema financeiro e crescimento, existe uma relação causal robusta entre essas duas variáveis (LEVINE, 1997; KING; LEVINE, 1993a, 1993b). Segundo Nogueira, Crocco e Figueiredo (2009), entre as variáveis utilizadas para medir essa relação, o indicador ativo financeiro/PIB é um dos mais utilizados, visto que dá a dimensão do sistema financeiro na economia local. 
A Tabela 5 mostra o peso diferenciado do sistema bancário fluminense, por intervalos de PIB, captado a partir desse indicador.

Tabela 5 - Ativos financeiros/PIB dos grupos selecionados: 2000-2014 (\%)

\begin{tabular}{rrrrrr}
\hline & Grupo 1 & Grupo 2 & Grupo 3 & $\begin{array}{c}\text { Região } \\
\text { metropolitana }\end{array}$ & $\begin{array}{c}\text { Municipio do Rio } \\
\text { de Janeiro }\end{array}$ \\
\hline 2000 & 15,92 & 19,22 & 17,65 & 540,96 & 720,81 \\
2001 & 17,31 & 31,72 & 17,01 & 700,07 & 944,53 \\
2002 & 21,61 & 24,31 & 18,83 & 890,89 & $1.203,82$ \\
2003 & 37,37 & 26,91 & 21,94 & 899,12 & $1.237,35$ \\
2004 & $15.444,34$ & 28,58 & 29,74 & 857,65 & $1.153,87$ \\
2005 & 141,35 & 42,89 & 47,85 & $1.334,10$ & $1.811,94$ \\
2006 & 260,52 & 51,90 & 92,77 & $1.286,63$ & $1.665,64$ \\
2007 & 22,70 & 24,16 & 15,88 & 498,64 & 705,99 \\
2008 & 22,24 & 24,95 & 14,05 & 382,01 & 513,24 \\
2009 & 24,03 & 25,97 & 26,81 & 399,16 & 541,06 \\
2010 & 25,62 & 27,83 & 19,45 & 907,01 & $1.254,29$ \\
2011 & 30,13 & 30,02 & 20,85 & 854,40 & $1.177,61$ \\
2012 & 33,66 & 27,44 & 21,87 & 846,12 & $1.152,32$ \\
2013 & 35,89 & 30,15 & 24,10 & 796,12 & $1.089,55$ \\
2014 & 37,61 & 32,69 & 27,37 & 893,05 & $1.247,61$ \\
\hline
\end{tabular}

Fonte: BCB (2017a) e IBGE (2017).

De acordo com a Tabela 5, o grupo 1 apresentou níveis maiores que 100\% nos anos de 2004 a 2006, alcançando, em 2004, o valor anormal de 15.444,34\%. Decompondo esse grupo, pode-se perceber que o crescimento desse período foi influenciado pelos municípios de Bom Jardim, Mendes e Porciúncula, cujas contas de compensação ${ }^{16}$ apresentaram valores altos para o período.

A Tabela 5 indica que somente a região metropolitana, que inclui o município carioca, apresenta valores maiores que 100\% durante todo o período, o que significa que nessa região o sistema financeiro aloca um volume de recursos superior ao seu PIB gerado. Em última instância, sugere uma drenagem de recursos para essa região e, ainda, o fato de que operações de crédito de volume mais

16 De acordo com o Manual de Normas do Sistema Financeiro (BCB, 2017b), as contas de compensação devem ser utilizadas para registro de quaisquer atos que possam transformar-se em direito, ganho, obrigação, perda, risco ou ônus efetivos, decorrentes de acontecimentos futuros, previstos ou fortuitos. Além de o conceito das contas de compensação ser muito amplo, o BCB não disponibiliza essa conta de forma detalhada, apenas disponibiliza o total, dessa forma, não é possível explicar a causa do valor encontrado no grupo 1 em 2004. 
elevado frequentemente são feitas na capital do estado, mesmo que relacionadas a atividades econômicas em outro município.

\subsection{Estratégias Bancárias Regionais}

A identificação de estratégias bancárias diferenciadas no espaço não é uma tarefa fácil. Primeiro, pela ausência de dados satisfatórios para uma análise da questão regional sob a ótica financeira e monetária. Segundo, pelo elevado grau de associação existente entre as regiões, pois há sempre a possibilidade de que o que ocorre em uma região ser consequência de eventos ocorridos em outras regiões que não a analisada. Esse fato é ainda mais relevante no caso brasileiro, no qual o sistema bancário é composto basicamente por grandes bancos nacionais, com agências espalhadas por todo o país e poucos bancos regionais. Apesar disso, acredita-se que há fortes indicações no sentido de se identificar essas estratégias, mesmo considerando-se as questões supracitadas. Assim, alguns indicadores foram elaborados e, apesar de serem apresentados isoladamente, devem ser considerados em seu conjunto para a identificação dessas estratégias.

Para se avaliar o impacto dos fatores monetários sobre o crédito regional, foi utilizado índice de preferência pela liquidez, seguindo-se a metodologia elaborada pelos pesquisadores ligados ao Laboratório de Estudos em Moeda e Território (LE$\mathrm{MTe}$ ) do Centro de Desenvolvimento e Planejamento Regional da Universidade Federal de Minas Gerais (Cedeplar/UFMG). A preferência pela liquidez dos bancos (PLB) mede a maior ou menor disposição dos bancos em manterem-se mais ou menos líquidos (NOGUEIRA; CROCCO; FIGUEIREDO, 2009). Trata-se da razão entre o item mais líquido do passivo dos bancos (total dos depósitos à vista) e o item menos líquido do ativo (total dos créditos concedidos). Desse modo, tem-se que:

$$
\mathrm{PLB}=\mathrm{DV} / \mathrm{OC}
$$

em que DV é o total dos depósitos à vista e OC são as operações de crédito.

Assim, quanto maior o indicador PLB, maior a preferência pela liquidez do banco, ou seja, menor a sua disposição em emprestar (em se tornar menos líquido).

De acordo com os dados da Tabela 6, os municípios menos desenvolvidos, com PIB entre $\mathrm{R} \$ 50$ e 200 milhões, apresentaram os maiores níveis de preferência pela liquidez durante quase toda a série. Entretanto, observa-se que há uma redução desses valores de 0,45 , em 2000, para 0,15 em 2014. Já a região metropolitana e o município do Rio de Janeiro - mais desenvolvidos - obtiveram os menores índices, como seria de se esperar. Entretanto, no período de 2005 a 2007, o grupo 
2 teve índices menores ou iguais (2005) ao município do Rio de Janeiro, sendo menor que o grupo 3 entre 2001 e 2014.

Tabela 6 - Preferência pela liquidez dos bancos: cidades fluminenses agregadas segundo o PIB de 2005* (2000-2014)

\begin{tabular}{lccccc}
\hline & Grupo 1 & Grupo 2 & Grupo 3 & $\begin{array}{c}\text { Região } \\
\text { metropolitana }\end{array}$ & $\begin{array}{c}\text { Município do Rio de } \\
\text { Janeiro }\end{array}$ \\
\hline 2000 & 0,45 & 0,37 & 0,36 & 0,12 & 0,12 \\
2001 & 0,43 & 0,32 & 0,45 & 0,17 & 0,16 \\
2002 & 0,40 & 0,30 & 0,55 & 0,21 & 0,20 \\
2003 & 0,34 & 0,29 & 0,48 & 0,22 & 0,21 \\
2004 & 0,32 & 0,27 & 0,46 & 0,25 & 0,24 \\
2005 & 0,28 & 0,26 & 0,42 & 0,27 & 0,26 \\
2006 & 0,26 & 0,24 & 0,40 & 0,29 & 0,28 \\
2007 & 0,25 & 0,23 & 0,38 & 0,29 & 0,29 \\
2008 & 0,24 & 0,23 & 0,33 & 0,21 & 0,21 \\
2009 & 0,22 & 0,22 & 0,30 & 0,20 & 0,19 \\
2010 & 0,22 & 0,23 & 0,29 & 0,18 & 0,18 \\
2011 & 0,21 & 0,20 & 0,27 & 0,17 & 0,17 \\
2012 & 0,18 & 0,19 & 0,22 & 0,16 & 0,16 \\
2013 & 0,17 & 0,16 & 0,18 & 0,15 & 0,14 \\
2014 & 0,15 & 0,14 & 0,16 & 0,12 & 0,12 \\
Média & 0,27 & 0,24 & 0,35 & 0,20 & 0,20 \\
\hline
\end{tabular}

Fonte: BCB (2017a).

Nota: Ver nota de rodapé $\mathrm{n}^{\mathrm{O}} 12$.

Embora o município do Rio de Janeiro apresente o menor indicador de preferência pela liquidez, observa-se que aumentou durante o período de 2000 a 2007, quando atinge o maior valor (0,29), decrescendo de 2008 a 2014, alcançando o valor inicial da série em $2000(0,12)$. O crescimento desse índice pode ser explicado pelo fato de o volume de depósitos à vista ter triplicado de 2000 para 2007, enquanto que o crédito concedido dobrou, conforme pode ser visto na tabela a seguir. Tanto os depósitos à vista quanto as operações de crédito cresceram, contudo o primeiro cresceu mais que proporcionalmente que o segundo, causando, assim, o aumento da razão entre esses dois indicadores. Quanto ao período de 2008 a 2014, as operações de crédito cresceram mais que proporcionalmente aos depósitos à vista, ocasionando a redução da PLB. Decompondo-se os grupos, pode-se perceber que, na região metropolitana do Rio de Janeiro, o município carioca é o que induz o aumento desse indicador. As demais cidades que compõem 
o grupo mantêm o índice mais ou menos constante durante toda a série. Isso também revela que a PLB das cidades de porte médio está decrescendo, o que pode indicar uma tendência à desconcentração de crédito no estado.

A Tabela 7 apresenta a evolução da participação dos depósitos à vista e das operações de crédito por grupo. Se comparados os dois indicadores, percebe-se que tanto os depósitos à vista quanto as operações de crédito se concentram fortemente na região metropolitana, principalmente no município do Rio de Janeiro. Entretanto, a participação carioca nos depósitos estaduais é menor que a participação das operações de crédito, o que pode indicar uma drenagem de recursos das demais regiões para a cidade do Rio de Janeiro, ou seja, enquanto a média dos depósitos cariocas representa $78,86 \%$ do estado, as operações de crédito correspondem a $84,79 \%$.

Tabela 7 - Participação (\%) dos grupos nos depósitos à vista e operações de crédito do estado

\begin{tabular}{cccccccccccc}
\hline & Grupo 1 & Grupo 2 & Grupo 3 & \multicolumn{2}{c}{$\begin{array}{c}\text { Região } \\
\text { metropolitana }\end{array}$} & \multicolumn{2}{c}{$\begin{array}{c}\text { Municipio } \\
\text { do Rio de } \\
\text { Janeiro }\end{array}$} \\
\hline & DV & OC & DV & OC & DV & OC & DV & OC & DV & OC \\
\hline 2000 & 0,81 & 0,24 & 1,34 & 0,48 & 9,39 & 3,53 & 88,46 & 95,75 & 79,39 & 89,96 \\
2001 & 0,89 & 0,39 & 1,37 & 0,81 & 10,27 & 4,27 & 87,48 & 94,54 & 77,94 & 89,16 \\
2002 & 0,81 & 0,46 & 1,21 & 0,9 & 9,69 & 3,97 & 88,29 & 94,67 & 79,36 & 90,52 \\
2003 & 0,78 & 0,53 & 1,17 & 0,93 & 9,23 & 4,36 & 88,83 & 94,18 & 79,84 & 89,10 \\
2004 & 0,73 & 0,61 & 1,11 & 1,08 & 8,8 & 5,10 & 89,37 & 93,21 & 80,49 & 87,53 \\
2005 & 0,74 & 0,73 & 1,13 & 1,22 & 8,8 & 5,81 & 89,34 & 92,23 & 80,23 & 85,53 \\
2006 & 0,66 & 0,75 & 1,04 & 1,29 & 8,44 & 6,29 & 89,85 & 91,67 & 81,01 & 84,40 \\
2007 & 0,60 & 0,71 & 0,94 & 1,20 & 7,92 & 6,20 & 90,54 & 91,89 & 82,05 & 84,76 \\
2008 & 0,72 & 0,68 & 1,18 & 1,13 & 8,96 & 6,03 & 89,14 & 92,16 & 78,98 & 85,29 \\
2009 & 0,76 & 0,72 & 1,28 & 1,19 & 9,33 & 6,49 & 88,63 & 91,59 & 78,32 & 84,28 \\
2010 & 0,82 & 0,72 & 1,40 & 1,18 & 9,93 & 6,93 & 87,86 & 91,18 & 76,71 & 83,27 \\
2011 & 0,94 & 0,79 & 1,43 & 1,27 & 10,25 & 8,17 & 87,38 & 89,78 & 76,29 & 80,44 \\
2012 & 0,91 & 0,82 & 1,47 & 1,27 & 9,86 & 8,85 & 87,76 & 89,06 & 77,03 & 78,96 \\
2013 & 0,93 & 0,81 & 1,40 & 1,25 & 9,70 & 9,05 & 87,97 & 88,90 & 77,28 & 78,77 \\
2014 & 0,94 & 0,79 & 1,37 & 1,21 & 9,43 & 8,60 & 88,27 & 89,41 & 77,94 & 79,92 \\
Média & 0,80 & 0,65 & 1,26 & 1,09 & 9,33 & 6,24 & 88,61 & 92,01 & 78,86 & 84,79 \\
\hline
\end{tabular}

Fonte: BCB (2017a).

Nota: OC: operações de crédito; DV: depósitos à vista. 
De acordo com a Tabela 7, o município do Rio de Janeiro é responsável por aproximadamente 80\% das operações de crédito estaduais no ano de 2014 . Apesar do peso desse município, tanto no estado quanto na região metropolitana sua participação vem caindo no período de 2003 a 2014 e, consequentemente, conduzindo a queda da região metropolitana. Em contrapartida, o grupo 1 mais que triplicou a sua participação e o grupo 2 mais que dobrou, o que evidencia uma certa desconcentração da oferta de crédito no estado do Rio de Janeiro, por conta do aumento maior da participação relativa dos municípios menores em termos de renda.

A Tabela 8 decompõe as operações de crédito em empréstimos e financiamentos pelos grupos. A evolução desses indicadores evidencia certa tendência à desconcentração de crédito no estado, pois a região metropolitana apresenta valores decrescentes para todo o período em detrimento das demais regiões, cujas tendências é de crescimento. 


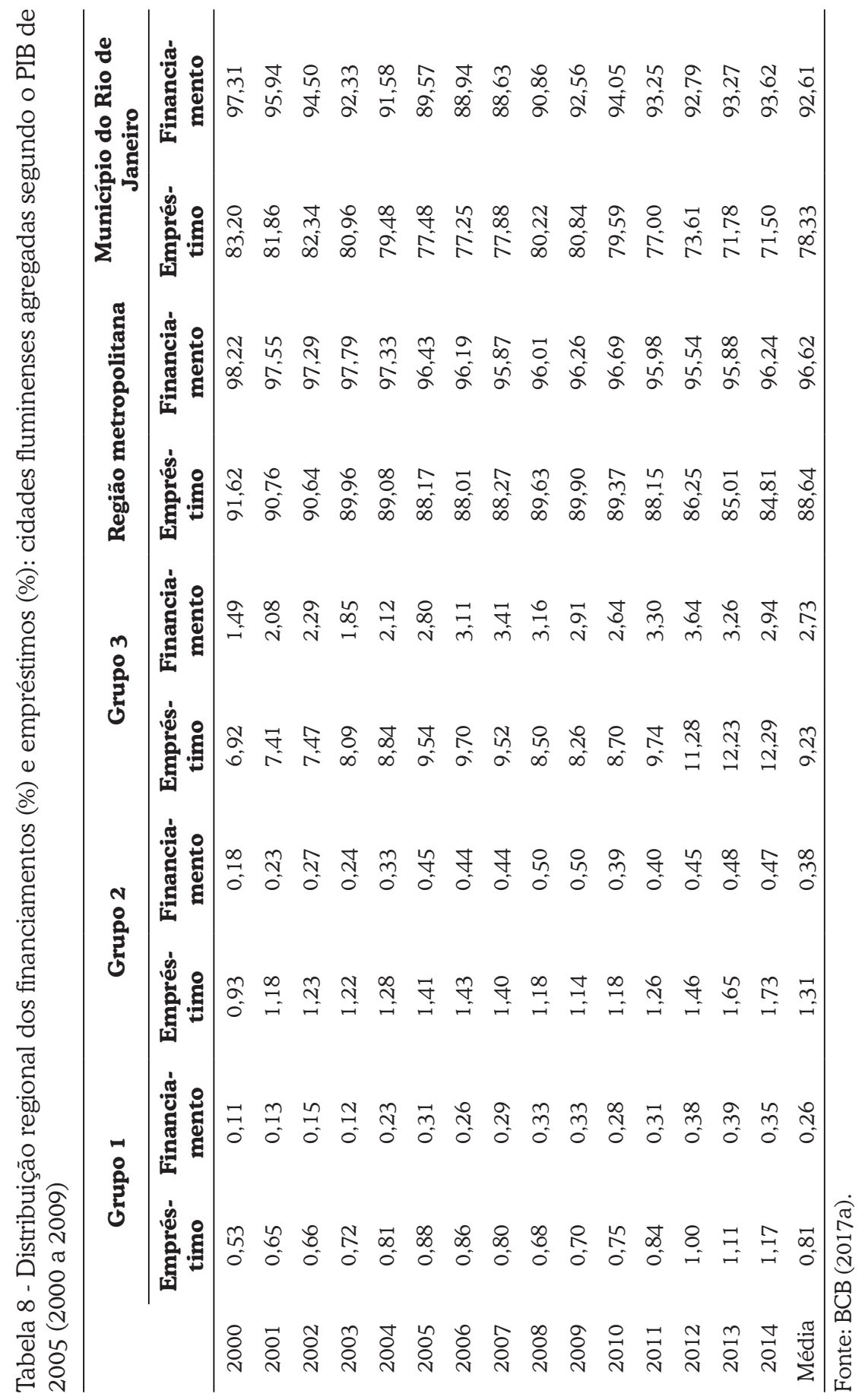

Análise Econômica, Porto Alegre, v. 38, n. 75, p. 103-130, mar. 2020. 
Pode-se argumentar que a concentração espacial do crédito seja apenas um reflexo do peso econômico dos municípios. De fato, é de se esperar que regiões com maiores PIB apresentem uma demanda por crédito mais elevada e, dessa forma, uma maior participação relativa na sua distribuição. Contudo, outros fatores afetam o comportamento da oferta de crédito, como as estratégias de expansão bancária - como no caso da tendência à bancarização de segmentos de baixa renda da população (DYMSKI, 2007) e a tendência à melhoria na distribuição de renda no país como um todo.

Outro indicador elaborado para identificar as estratégias bancárias regionais é o índice regional de crédito (IRC). O IRC mostra se a concessão de crédito em determinado grupo é maior do que o que poderia ser esperado em função do produto existente na região (PIB). O IRC é calculado a partir da razão entre a participação relativa de um grupo de municípios no total de crédito concedido no estado do Rio de Janeiro e a participação relativa dessa mesma região no PIB estadual, ${ }^{17}$ de tal modo que:

$$
\text { IRC }=\frac{\frac{O C_{\text {mun }}}{O C_{\text {est }}}}{\frac{P I B_{\text {mun }}}{\text { PIB }_{\text {est }}}}
$$

em que $\mathrm{OC}_{\text {mun }}$ são as operações de crédito do município, $\mathrm{OC}_{\text {est }}$ são as operações de crédito do estado, PIB $_{\text {mun }}$ é o PIB do município e PIB $_{\text {est }}$ é o PIB do estado.

Dessa forma, tem-se um índice que, quando superior a 1 , sugere que os municípios recebem uma fatia dos empréstimos e financiamentos concedidos no estado maior do que sua contribuição para o PIB fluminense e que, com valor menor que 1 , recebem um volume de crédito proporcionalmente inferior ao PIB regional. Desse modo, a Tabela 9 mostra que a participação da oferta de crédito da região metropolitana é maior que a participação na produção, o que indica que o crédito é mais concentrado que o nível de produção entre as regiões. Essa concentração pode ser explicada em parte pelo fato de que grande parte das empresas está sediada em municípios mais desenvolvidos e as operações de crédito realizadas são contabilizadas no município sede, embora os recursos sejam aplicados em projetos de outras regiões.

17 Esse indicador é uma adaptação do quociente locacional amplamente utilizado na literatura de economia regional para determinar a existência ou não de especialização produtiva em uma região específica. 
Tabela 9 - Índice regional de crédito (Crédito/PIB): cidades fluminenses (2000 a 2014)

\begin{tabular}{lccccc}
\hline & Grupo I & Grupo 2 & Grupo 3 & $\begin{array}{c}\text { Região } \\
\text { metropolitana }\end{array}$ & $\begin{array}{c}\text { Município do Rio } \\
\text { de Janeiro }\end{array}$ \\
\hline 2000 & 0,15 & 0,18 & 0,15 & 1,33 & 1,69 \\
2001 & 0,24 & 0,30 & 0,18 & 1,32 & 1,69 \\
2002 & 0,30 & 0,33 & 0,15 & 1,35 & 1,77 \\
2003 & 0,34 & 0,36 & 0,16 & 1,37 & 1,82 \\
2004 & 0,37 & 0,38 & 0,18 & 1,37 & 1,78 \\
2005 & 0,53 & 0,45 & 0,18 & 1,43 & 1,87 \\
2006 & 0,55 & 0,50 & 0,18 & 1,48 & 1,91 \\
2007 & 0,51 & 0,46 & 0,20 & 1,43 & 1,90 \\
2008 & 0,45 & 0,43 & 0,17 & 1,55 & 1,98 \\
2009 & 0,46 & 0,42 & 0,22 & 1,38 & 1,76 \\
2010 & 0,48 & 0,43 & 0,22 & 1,41 & 1,80 \\
2011 & 0,55 & 0,46 & 0,25 & 1,43 & 1,80 \\
2012 & 0,60 & 0,40 & 0,26 & 1,46 & 1,79 \\
2013 & 0,58 & 0,39 & 0,28 & 1,41 & 1,74 \\
2014 & 0,52 & 0,38 & 0,27 & 1,41 & 1,79 \\
\hline
\end{tabular}

Fonte: IBGE (2017) e BCB (2017a).

Segundo a definição do IRC, o município do Rio de Janeiro recebeu, de 2000 a 2014, uma fatia das operações de crédito aproximadamente uma vez e meia maior que a sua contribuição para o PIB estadual. O IRC da região metropolitana também foi maior que 1 durante todo o período, confirmando o peso dessa região no estado. Pode se observar também que, de 2000 para 2014, os grupos 1 e 2 passaram de um IRC de 0,15 e 0,18, respectivamente, para 0,52 e 0,38. Apesar de o IRC da região metropolitana também ter aumentado de 1,69, em 2000, para 1,79, em 2014, esse crescimento foi proporcionalmente menor que o apresentado pelos outros grupos, o que parece corroborar a hipótese de desconcentração de crédito no estado no período analisado, seguindo a tendência de desconcentração espacial da produção vista na seção 2 .

\subsection{Número de Agências e Atendimento Bancário}

Em 15 anos, o número de agências do estado do Rio de Janeiro cresceu de 1.555, em 2000, para 2.120 em 2014. Esse crescimento foi basicamente explicado pelo aumento do número de agências no município do Rio de Janeiro, que tinha 1.000 agências, em 2000, e passou para 1.248 em 2014. 
De modo geral, nos anos 2000 houve uma expansão da rede de agências em todos os grandes conglomerados financeiros (Banco do Brasil, Itaú, Bradesco, Santander, Caixa Econômica Federal e HSBC), um movimento que acompanha a expansão da atividade de intermediação financeira no país, conforme pode ser visto na Tabela 10.

Tabela 10 - Número de agências: Brasil e regiões

\begin{tabular}{ccccccc}
\hline & Norte & Nordeste & Centro-oeste & Sudeste & Sul & Brasil \\
\hline 2000 & 557 & 2.319 & 1.189 & 8.895 & 3.364 & 16.324 \\
2001 & 562 & 2.362 & 1.228 & 9.211 & 3.407 & 16.770 \\
2002 & 580 & 2.390 & 1.259 & 9.318 & 3.440 & 16.987 \\
2003 & 583 & 2.335 & 1.264 & 9.204 & 3.398 & 16.784 \\
2004 & 643 & 2.495 & 1.302 & 9.286 & 3.477 & 17.203 \\
2005 & 672 & 2.536 & 1.326 & 9.501 & 3.545 & 17.580 \\
2006 & 704 & 2.564 & 1.351 & 9.812 & 3.598 & 18.029 \\
2007 & 724 & 2.621 & 1.382 & 10.143 & 3.655 & 18.525 \\
2008 & 760 & 2.702 & 1.429 & 10.466 & 3.715 & 19.072 \\
2009 & 798 & 2.788 & 1.485 & 11.122 & 3.809 & 20.002 \\
2010 & 827 & 2.824 & 1.505 & 10.813 & 3.781 & 19.750 \\
2011 & 984 & 3.214 & 1.610 & 11.352 & 4.072 & 21.232 \\
2012 & 1.066 & 3.474 & 1.698 & 11.695 & 4.246 & 22.179 \\
2013 & 1.106 & 3.611 & 1.819 & 11.992 & 4.351 & 22.879 \\
2014 & 1.135 & 3.666 & 1.847 & 12.077 & 4.365 & 23.090 \\
\hline
\end{tabular}

Fonte: BCB (2017a).

Uma análise da Tabela 11, que mostra a evolução do número de agências por grupo no período de 2000 a 2014, indica que houve um crescimento em todos os grupos analisados, com destaque para a os grupos 1 e 3, que cresceram $78,95 \%$ e $58,74 \%$, respectivamente, no período. Houve também um crescimento considerável do número de agências da região metropolitana, um acréscimo de 31,76\%. Em termos absolutos, houve um acréscimo de 390 agências na região metropolitana, de 121 no grupo 3 e de 45 no grupo 1. Das 390 agências da região metropolitana, 248 estão localizadas no município do Rio de Janeiro. 
Tabela 11 - Número de agências

\begin{tabular}{lcccccc}
\hline & Grupo 1 & Grupo 2 & Grupo 3 & $\begin{array}{c}\text { Região } \\
\text { metropolitana }\end{array}$ & $\begin{array}{c}\text { Municipio do } \\
\text { Rio de Janeiro }\end{array}$ & Total \\
\hline 2000 & 57 & 64 & 206 & 1.228 & 1.000 & 1.555 \\
2001 & 57 & 64 & 213 & 1.306 & 1.061 & 1.640 \\
2002 & 59 & 67 & 217 & 1.313 & 1.070 & 1.656 \\
2003 & 59 & 68 & 215 & 1.276 & 1.038 & 1.618 \\
2004 & 63 & 68 & 220 & 1.263 & 1.022 & 1.614 \\
2005 & 67 & 70 & 228 & 1.284 & 1.034 & 1.649 \\
2006 & 69 & 70 & 229 & 1.334 & 1.065 & 1.702 \\
2007 & 67 & 70 & 245 & 1.372 & 1.089 & 1.754 \\
2008 & 69 & 70 & 260 & 1.420 & 1.114 & 1.819 \\
2009 & 70 & 73 & 289 & 1.584 & 1.250 & 2.016 \\
2010 & 69 & 69 & 276 & 1.445 & 1.135 & 1.859 \\
2011 & 98 & 74 & 299 & 1.513 & 1.181 & 1.984 \\
2012 & 99 & 75 & 311 & 1.564 & 1.213 & 2.049 \\
2013 & 102 & 74 & 322 & 1.605 & 1.244 & 2.103 \\
2014 & 102 & 73 & 327 & 1.618 & 1.248 & 2.120 \\
Média & 74 & 70 & 257 & 1.408 & 1.118 & 1.809 \\
\hline Fon & 69 & & & & \\
\hline
\end{tabular}

Fonte: BCB (2017a).

Dos 87 municípios assistidos em 2000, apenas Duque de Caxias, Niterói, Rio de Janeiro e Petrópolis possuíam 30 ou mais agências, os três primeiros fazem parte da região metropolitana, enquanto o último faz parte do grupo 3. Em 2014, além dos municípios citados, Campos dos Goytacazes, Macaé, Volta Redonda, Nova Iguaçu e São Gonçalo passaram a ter 30 ou mais agências (40, 30, 33, 47 e 47 respectivamente), os três primeiros fazem parte do grupo 3, enquanto que os demais fazem parte da região metropolitana. Isso indica que há uma tendência de dinamização do grupo 3, visto que a abertura de várias agências em um mesmo município ou região pode ser entendida como uma evidência de dinamismo do município ou região. Campos e Macaé fazem parte da Bacia de Campos, conforme visto anteriormente, uma região que tem se desenvolvido graças à exploração de petróleo e gás. Já em Volta Redonda, está localizada a Companhia Siderúrgica Nacional, além de outras empresas de cimento, siderúrgicas e metalomecânica, o que pode explicar o desenvolvimento desse município.

Durante todo o período, todos os municípios fluminenses tinham pelo menos uma agência, com exceção de Carapebus, Comendador Levy Gasparian, Iguaba Grande, Japeri e Mesquita. Os quatro primeiros não possuíam agência até 2003 
e o último foi emancipado do município de Nova Iguaçu em setembro de 1999 , passando a ter agência em 2001.

Na Tabela 12, relaciona-se população (1.000 habitantes) por agência para se comparar o acesso da população dos grupos a serviços bancários, inclusive a crédito. Acredita-se que, quanto menor a razão população por agência, maior o acesso da população ao atendimento bancário e, consequentemente, maior a oferta de crédito na região.

Tabela 12 - População (1.000 habitantes)/agência

\begin{tabular}{cccccc}
\hline & Grupo 1 & Grupo 2 & Grupo 3 & $\begin{array}{c}\text { Região } \\
\text { metropolitana }\end{array}$ & $\begin{array}{c}\text { Municipio do Rio } \\
\text { de Janeiro }\end{array}$ \\
\hline 2000 & 8,20 & 8,79 & 11,98 & 8,50 & 5,61 \\
2001 & 8,46 & 9,37 & 12,11 & 8,34 & 5,56 \\
2002 & 8,23 & 9,09 & 12,06 & 8,39 & 5,55 \\
2003 & 8,31 & 9,10 & 12,35 & 8,71 & 5,76 \\
2004 & 7,93 & 9,40 & 12,44 & 8,97 & 5,92 \\
2005 & 7,53 & 9,30 & 12,20 & 8,91 & 5,89 \\
2006 & 7,38 & 9,46 & 12,35 & 8,67 & 5,76 \\
2007 & 7,36 & 9,15 & 11,63 & 8,34 & 5,60 \\
2008 & 7,49 & 9,74 & 11,59 & 8,21 & 5,53 \\
2009 & 7,44 & 9,46 & 10,59 & 7,41 & 4,95 \\
2010 & 7,47 & 9,96 & 11,16 & 8,10 & 5,57 \\
2011 & 5,29 & 9,38 & 10,44 & 7,78 & 5,38 \\
2012 & 5,27 & 9,35 & 10,17 & 7,57 & 5,27 \\
2013 & 5,15 & 9,59 & 9,97 & 7,43 & 5,17 \\
2014 & 5,17 & 9,81 & 9,92 & 7,40 & 5,17 \\
Média & 7,11 & 9,40 & 11,40 & 8,18 & 5,51 \\
\hline
\end{tabular}

Fonte: BCB (2017a) e IBGE (2017).

Todos os grupos, exceto o grupo 2, apresentam uma queda na relação população por agência. Isso significa que o número de agências está aumentando mais que proporcionalmente que o número de habitantes, ou seja, a população está tendo mais acesso aos serviços bancários.

De acordo com essa hipótese, o grupo 1, por apresentar a menor razão, deveria ter uma maior concessão de crédito, entretanto, se comparada a Tabela 12 com a Tabela 7 (participação dos grupos nos depósitos à vista e operações de crédito do estado), percebe-se que o grupo 1 possui a menor participação nas operações de crédito realizadas no estado. Além disso, dois municípios (Comendador Levy Gasparian e Iguaba Grande) integrantes do grupo 1 não tinham agências até 
2003. De 2000 a 2009, esse grupo apresentava o menor número de agências quando comparado aos demais (Tabela 11). Essa contradição pode ser explicada pelo tamanho da população, que representa cerca de 3\% da população do estado, ou seja, o número de habitantes dessa região é muito baixo, induzindo a queda da razão.

A região metropolitana apresenta o segundo menor indicador, corroborando a hipótese de maior acesso ao crédito, o que também pode ser visto pela alta participação dessa região nas operações de crédito concedidas no estado, conforme visto na Tabela 7.

A Tabela 13 apresenta a relação do total das operações de crédito dividido pelo número de agências de cada grupo. Todos os grupos aumentaram as operações de crédito por agência. Entretanto, o grupo cujo indicador é menor em termos absolutos aumentou em maiores proporções quando comparado aos grupos com maiores indicadores. Associando esse indicador ao número de agências visto na Tabela 11 , observa-se que esse grupo obteve o maior crescimento $(78,95 \%)$, indicando um maior dinamismo dessa região.

Tabela 13 - Operações de crédito em reais por agência*

$\begin{array}{llllcc} & \text { Grupo 1 } & \text { Grupo 2 } & \text { Grupo 3 } & \begin{array}{c}\text { Região } \\ \text { metropolitana }\end{array} & \begin{array}{c}\text { Municipio do } \\ \text { Rio de Janeiro }\end{array} \\ 2000 & 3.600 .393 & 6.509 .125 & 15.006 .358 & 67.487 .374 & 77.891 .792 \\ 2001 & 4.539 .173 & 8.393 .322 & 13.552 .887 & 48.218 .155 & 56.012 .696 \\ 2002 & 4.835 .864 & 8.372 .768 & 11.639 .284 & 45.134 .793 & 53.008 .469 \\ 2003 & 4.947 .604 & 7.615 .048 & 11.498 .434 & 41.114 .001 & 47.865 .567 \\ 2004 & 5.331 .887 & 8.752 .011 & 12.958 .854 & 39.102 .889 & 45.314 .776 \\ 2005 & 5.950 .739 & 9.432 .893 & 14.169 .264 & 38.610 .585 & 44.445 .628 \\ 2006 & 6.176 .174 & 10.525 .557 & 15.925 .543 & 39.384 .729 & 45.502 .038 \\ 2007 & 7.204 .619 & 11.602 .429 & 17.429 .716 & 45.866 .195 & 53.412 .094 \\ 2008 & 7.931 .446 & 13.008 .023 & 19.435 .882 & 52.416 .810 & 61.811 .290 \\ 2009 & 8.740 .038 & 13.902 .377 & 19.439 .939 & 49.237 .608 & 57.492 .375 \\ 2010 & 9.646 .998 & 15.860 .531 & 23.372 .055 & 58.726 .323 & 68.284 .216 \\ 2011 & 7.596 .692 & 16.259 .896 & 25.895 .212 & 56.255 .883 & 64.574 .472 \\ 2012 & 8.474 .787 & 17.474 .935 & 29.294 .014 & 58.597 .817 & 66.991 .340 \\ 2013 & 9.088 .826 & 19.422 .249 & 32.321 .701 & 63.729 .598 & 72.855 .855 \\ 2014 & 9.929 .716 & 21.228 .316 & 33.822 .904 & 71.052 .533 & 82.348 .463 \\ \text { Média } & 6.932 .997 & 12.557 .299 & 19.717 .470 & 51.662 .353 & 59.854 .071\end{array}$


O indicador de todos os grupos em 2014 é superior à média, evidenciando um forte crescimento a partir de 2007. A região metropolitana, com destaque para o Rio de Janeiro, é a que mais concede crédito por agência, embora os outros grupos apresentem indicadores crescentes, com crescimento relativo maior que a região metropolitana, o que parece evidenciar uma tendência à desconcentração de crédito no estado do Rio de Janeiro.

\section{Considerações Finais}

Existe um debate sobre a relação de causalidade entre desenvolvimento financeiro e desenvolvimento econômico. Essa questão ganhou ainda mais relevância diante do processo de consolidação do setor bancário e seus efeitos sobre a concessão de crédito, especificamente no caso brasileiro, no qual a consolidação do setor bancário ganhou força após a estabilização da economia em 1994. Nesse contexto, vários autores, através de diversas avaliações empíricas, concluíram que existe uma significativa desigualdade entre os estados brasileiros, tanto em termos de atendimento, quanto de oferta de crédito bancário, ou seja, há evidências de que os bancos agem de forma distinta no espaço, corroborando a abordagem da preferência pela liquidez diferenciada no espaço. Cabe ressaltar, contudo, que a tendência ao aprofundamento das desigualdades econômicas regionais causada por fatores monetário-creditícios, em função da maior preferência pela liquidez dos bancos na periferia, pode ser atenuada pela ação do governo, via bancos públicos. Contudo, Nogueira da Costa (2016, p. 48) ressalta que "[...] os pós-keynesianos, devido à teoria da preferência pela liquidez dos bancos, esperavam uma dependência de trajetória com retroalimentação que desigualaria ainda mais as rendas regionais. Porém, inovações como políticas públicas progressistas buscaram contrapor-se a essa trajetória de concentração de renda regional perversa socialmente.".

No caso do estado do Rio de Janeiro, a análise de indicadores financeiros (depósitos, operações de crédito, empréstimos, financiamentos e número de agências) indica que o crédito também é alocado de forma desigual entre os municípios fluminenses, resultado também encontrado no artigo de Nogueira, Crocco e Figueiredo (2009) para o estado de Minas Gerais. O presente estudo mostrou que há uma grande concentração bancária na região metropolitana, em particular no município carioca, cuja participação nas operações de crédito estadual foi superior a 78\% durante todo o período analisado neste trabalho.

Os indicadores bancários do estado do Rio de Janeiro analisados parecem evidenciar um movimento de desconcentração do crédito e do atendimento bancário, reforçando as tendências de desenvolvimento econômico fora da região metropolitana. As cidades do interior vêm apresentando um dinamismo diferen- 
ciado, com destaque para Campos dos Goytacazes, Macaé e Volta Redonda. As duas primeiras fazem parte da Bacia de Campos e têm como atividade principal a exploração de petróleo e gás, uma das atividades que mais cresceu no estado, enquanto a última é sede da Companhia Siderúrgica Nacional, responsável por grande parte da produção siderúrgica do estado.

Assim, quando relacionam-se os dados bancários com os dados relativos à distribuição da atividade econômica no território fluminense, pode-se concluir, com base na análise do período 2000-2014, que, embora tenha existido uma concentração de crédito maior que a concentração econômica na região metropolitana, as cidades do interior apresentaram um dinamismo diferenciado, evidenciando certa tendência à desconcentração do crédito, que tem acompanhado o movimento de crescimento da atividade econômica nesses municípios. Isso reforça a relação entre desenvolvimento econômico e financeiro e a concepção de que o movimento financeiro se concentra no entorno de cidades de forte dinamismo econômico, ou seja, de que o sistema bancário atua de forma distinta no espaço. Ainda assim, a concentração econômica e da atividade bancária na região metropolitana manteve-se em níveis elevados.

Embora a concentração bancária seja maior que a econômica, deve-se levar em conta que várias operações de crédito contabilizadas na região da sede das empresas têm seus recursos aplicados em projetos de outra região. De qualquer forma, esse tipo de análise não prejudica os resultados obtidos, mas indica que este artigo não esgota o assunto aqui tratado, sendo possível aprofundar a pesquisa.

Uma possibilidade de aprofundamento do trabalho seria analisar os fatores determinantes da disponibilidade regional de crédito, sendo a variável dependente o crédito per capita, verificando-se, assim, a hipótese de que as variáveis financeiras afetam o crescimento econômico.

Outra possibilidade seria investigar o que determina a localização de uma rede de agências bancárias em uma região. Nos indicadores analisados para o estado do Rio de Janeiro, verificou-se o aumento do número de agências no grupo 3, em especial em Campos e Volta Redonda. Porém, quais variáveis explicariam esse crescimento? Existe um PIB mínimo para a criação de uma agência ou é o tamanho da população que importa? Quais fatores poderiam explicar que os municípios de Carapebus, Comendador Levy Gasparian, Iguaba Grande, Japeri e Mesquita - que no ano inicial da série não tinham agência - passaram a ter pelo menos uma agência para cada um? Essas são questões que julgamos relevantes para aprofundamento em pesquisas futuras. 


\section{Referências}

ALMEIDA, D. B. C. Bancos e concentração de crédito no Brasil: 1995-2004. 100f. Dissertação (Mestrado) - Centro de Desenvolvimento e Planejamento Regional, Faculdade de Ciências Econômicas, Universidade Federal de Minas Gerais, Belo Horizonte, 2007.

AMADO, A. Moeda, financiamento, sistema financeiro e trajetórias de desenvolvimento regional desigual: a perspectiva pós-keynesiana. Revista de Economia Política, v. 18, n. 1, p. 76-89, jan./mar. 1998.

ARAÚJO, E.; DIAS, J. Endogeneidade do setor financeiro e crescimento econômico: uma análise empírica para a economia brasileira (1980-2003)". Revista Economia Contemporânea, v. 10, n. 3, p. 575-610, set./dez. 2006.

BCB. ESTBAN: estatística bancária mensal por município. [2017a]. Disponível em: http:// www4.bcb.gov.br/fis/cosif/estban.asp. Acesso em: 20 set. 2017.

BCB. COSIF: manual de normas do sistema financeiro nacional. [2017b]. Disponível em: https://www3.bcb.gov.br/aplica/cosif. Acesso em 20 out. 2017.

BARRAL NETO, J. F.; SILVA NETO, R. Uma nova trajetória para a economia fluminense: inflexão positiva graças ao interior. In: FAURÉ, Y. A.; HASENCLEVER, L.; SILVA NETO, R. (org.). Novos rumos para a economia fluminense: oportunidades e desafios do crescimento do interior. Rio de Janeiro: E-papers, 2008. p. 25-46.

BUENO, J. C. C.; CASARIN, L. O. B. Os recursos do petróleo e as perspectivas para os investimentos no estado do Rio de Janeiro. In: URANI, A.; GIAMBIAGI, F. (org.). Rio: a hora da virada. Rio de Janeiro: Elsevier, 2011. p. 40-50.

CAVALCANTE, A.; CROCCO, M.; GONZAGA, F. Preferência pela liquidez, sistema bancário e disponibilidade de crédito regional. Belo Horizonte: UFMG/Cedeplar, 2004. (Texto para Discussão, 237).

CRESPO, N. E. Campos dos Goytacazes perde a corrida do petróleo. In: PIQUET, R. Petróleo, royalties e região. Rio de Janeiro: Garamond, 2003, p. 239-256.

DYMSKI, G. Exclusão e eficiência: a transformação global do core banking, um estudo de caso sobre o Brasil. In: PAULA, L. F.; OREIRO, J. L. Sistema financeiro: uma análise do setor bancário brasileiro. Rio de Janeiro: Campus/Elsevier, 2007. p. 255-283.

DOW, S. C. Money and the economic process. Aldershot: Edward Elgar, 1993.

FREITAS, A. P. G.; PAULA, L. F. Concentração regional do crédito e consolidação bancária no Brasil: uma análise pós-real. Economia (ANPEC), v. 11, n.1, p. 97-123, jan./abr. 2010.

IBAM. Territórios simultaneamente beneficiados por programas federais e por pagamentos de royalties decorrentes de exploração de petróleo e gás natural: subsídios para o aperfeiçoamento da gestão para o desenvolvimento sustentável. Programa de Desenvolvimento Institucional das Administrações Locais. [Rio de Janeiro], 2009. Disponível em: http:/www.ibam.org.br/media/arquivos/estudos/royalties_rjaneiro.pdf. Acesso em: 24 jan. 2014. 
IBGE. Estatísticas. Disponível em: https:/www.ibge.gov.br/estatisticas/downloads-estatisticas. html Acesso em: 31 out. 2017.

KING, R. G.; LEVINE, R. Financial intermediation and economic development. In: MAYER, C.; VIVES, X. (ed.). Capital markets and financial intermediation. Cambridge: Cambridge University Press, 1993a. p. 156-189.

KING, R. G.; LEVINE, R. Finance and growth: Schumpeter might be right. Quarterly Journal of Economics, v. 108, n. 3, p. 717-738, 1993b.

LEVINE, R. Financial development and economic growth: views and agenda. Journal of Economic Literature, v. 35, n. 2, p. 688-726, jun. 1997.

MATOS, O. C. Desenvolvimento do sistema financeiro e crescimento econômico no Brasil: evidências de causalidade. Brasília, DF: Departamento de Estudos e Pesquisas do Banco Central do Brasil, 2002. (Trabalhos para Discussão, 49).

MENEZES, M.; CROCCO, M.; SANCHES, E.; AMADO, A. Sistema financeiro e desenvolvimento regional: notas exploratórias. In: PAULA, L. F.; OREIRO, J. L. (org.). Sistema financeiro: uma análise do setor bancário brasileiro. Rio de Janeiro: Elsevier, 2007. p. 285-305.

NATAL, J. L. A. O Estado do Rio de Janeiro pós-95: rede urbana, dinâmica econômica, questão social. Rio de Janeiro: Pubblicati, 2005.

NOGUEIRA, M.; CROCCO, M.; FIGUEIREDO, A. T. L. Estratégias bancárias diferenciadas no território: o caso de Minas Gerais. Belo Horizonte: UFMG/CEDEPLAR, 2009. (Texto para Discussão, n. 345).

NOGUEIRA DA COSTA, F. Interações entre componentes regionais do Sistema Bancário Nacional. Campinas: IE/UNICAMP, 2016. (Texto para Discussão, n. 265).

PAULA, L. F. Sistema financeiro, financiamento e bancos: uma abordagem keynesiana. Rio de Janeiro: Campus, 2014.

PIQUET, R. Da cana ao petróleo: uma região em mudança. In: PIQUET, R. Petróleo, Royalties e região. Rio de Janeiro: Garamond, 2003. p. 219-238.

REICHSTUL, D.; LIMA, G. T. Causalidade entre crédito bancário e nível de atividade econômica na região Metropolitana de São Paulo: algumas evidências empíricas. Estudos Econômicos, v. 36, n. 4, p. 779-801, out./dez. 2006.

SANTOS, A. M. P. Economia, espaço e sociedade no Rio de Janeiro. Rio de Janeiro: Ed. FGV, 2003.

SANTOS, A. M. P. Cidades médias e reestruturação espacial na economia fluminense. In: CARNEIRO, S.; SANT'ANNA, M. J. (org.). Cidades: olhares e trajetórias. Rio de Janeiro: Garamond, 2009. p. 137-165.

SILVA, E. M. G. Cadeias produtivas e complexos industriais da economia fluminense. $133 \mathrm{f}$. Dissertação (Mestrado em Economia) - Centro de Desenvolvimento e Planejamento 
Regional, Faculdade de Ciências Econômicas, Universidade Federal de Minas Gerais, Belo Horizonte, 2007.

SORGATO, L. A.; FERREIRA JR., R. R. Desigualdade financeira regional: vazamento de depósitos no Nordeste brasileiro. Revista Econômica do Nordeste, v. 45, v. 2, p. 17-31, 2014.

VASCONCELOS, M. R.; FICIDJI, J. R.; SCORZAFAVE, L. G.; ASSIS, D. L. O todo e as partes: uma análise da desigualdade de crédito entre os estados brasileiros e os determinantes do crédito bancário com a aplicação de dados em painel. Economia e Sociedade, v. 13, n. 22, p. 123-149, jan./jun. 2004.

Recebido em: 21/05/2017.

Aceito em: 03/05/2018.

(cc) BY 